Journal of Mathematics and Statistics 6 (3): 279-285, 2010

ISSN 1549-3644

(C) 2010 Science Publications

\title{
Ordinal Logistic Regression Model: An Application to Pregnancy Outcomes
}

\author{
${ }^{1}$ K.A. Adeleke and ${ }^{2}$ A.A. Adepoju \\ ${ }^{1}$ Department of Statistics, University of Ibadan, Ibadan \\ ${ }^{2}$ Department of Mathematics, University of mines and Technology, Tarkwa, Ghana
}

\begin{abstract}
Problem statement: This research aimed at modeling a categorical response i.e., pregnancy outcome in terms of some predictors, determines the goodness of fit as well as validity of the assumptions and selecting an appropriate and more parsimonious model thereby proffered useful suggestions and recommendations. Approach: An ordinal logistic regression model was used as a tool to model the three major factors viz., environmental (previous cesareans, service availability), behavioral (antenatal care, diseases) and demographic (maternal age, marital status and weight) that affected the outcomes of pregnancies (livebirth, stillbirth and abortion). Results: The fit, of the model was illustrated with data obtained from records of 100 patients at Ijebu-Ode, State Hospital in Nigeria. The tested model showed good fit and performed differently depending on categorization of outcome, adequacy in relation to assumptions, goodness of fit and parsimony. We however see that weight and diseases increase the likelihood of favoring a higher category i.e., (livebirth), while medical service availability, marital status age, antenatal and previous cesareans reduce the likelihood/chance of having stillbirth. Conclusion/Recommendations: The odds of being in either of these categories i.e., livebirth or stillbirth showed that women with baby's weight less than $2.5 \mathrm{~kg}$ are 18.4 times more likely to have had a livebirth than are women with history of babies $\geq 2.5 \mathrm{~kg}$. Age (older age and middle aged) women are one halve (1.5) more likely to occur than lower aged women, likewise is antenatal, (high parity and low parity) are more likely to occur 1.5 times than nullipara.
\end{abstract}

Key words: Ordinal logistics, regression model, pregnancy outcome, categorical data, proportional odds

\section{INTRODUCTION}

Logistic regression, the goal is the same as in Ordinary Least Squares (OLS) regression: we wish to model a dependent variable in terms of one or more independent variables. The OLS method which is commonly used to predict dependent variable based on the knowledge of one or more independent variables is useful only for continuous dependent variables; while logistic regression is for dependent variables that are categorical. The dependent variable may have two categories (e.g., alive/dead; male/female; republican/democrat) or more than two categories. If it has more than two categories they may be ordered (e.g., none/some/a lot) or unordered (e.g., married/single/divorced/widowed/other). Logistic regression deals with these issues by issues by transforming the dependent variable, (Dayton, 1992) extended the technique of a multiple logistic regression analysis to research situation where the outcome variable is categorical thereby modeling the survival of infancy. Ananth and Kleinbaum (1997) in a review study, considered the continuation-ratio and proportional odds model as well as three other less frequently used models: the unconstraint partial proportional odds model, constraint partial proportional odds model and stereotype logistic model. Ordinal logistic regression model is sometimes referred to as the constrained cumulative logit model originally proposed by Walker and Duncan (1967) and later called proportional odds model by (McCullagh, 1980; Ananth and Kleinbaum, 1997; Agresti, 2007; Hosmer and Lemeshow, 2000). Many quality of life scales are ordinal, "statistical methods such as ordinal regression models have been reviewed on a number of times", said (Lall et al., 2002). They however, applied the model using data generating methods and making use of proportional odds model, partial proportional odds model and stereotypy model. Dong (2007) applied the models for ordinal response study, a self efficacy in colorectal cancer screening. Adepoju and Adegbite (2009) also used ordinal logistic model to study the relationship between staff categories (as outcome variable) Gender, Indigenous status, educational qualification, previous experience and age as explanatory variables. This study focuses on model a categorical response i.e., pregnancy outcome, interpretation of the model parameters, select 
appropriate and more parsimonious model and their implication for quality of live, health and epidemiological study.

\section{MATERIALS AND METHODS}

Ordinal logistic regression model: Ordinal outcomes are analyzed by logistic regression model. When a dependent variable is ordinal, we face a quandary. Sometimes we forget about the ordering and fit a multinomial logit that ignores any ordering of the values of the dependent variable. The same model is fit if groups are defined by color of a car driven or severity of disease. The most commonly used proportional odds model. The model is:

$$
\mathrm{y}_{\mathrm{i}}^{*}=\mathrm{x}_{\mathrm{i}} \beta+\varepsilon_{\mathrm{i}}
$$

However, since the dependent variable is categorized, we must instead use:

$$
c_{x}(x)=\ln \left[\frac{P(Y \leq j \mid x)}{P(Y>j \mid x)}\right]
$$

and:

$$
\begin{aligned}
\operatorname{In}\left(\frac{\Sigma \operatorname{pr}(\text { event })}{1-\Sigma \operatorname{pr}(\text { event })}\right)= & \beta_{0}+\beta_{1} X_{1}+\beta_{2} X_{2} \\
& +\beta_{3} X_{3}+\ldots+\beta_{k} X_{k}
\end{aligned}
$$

Or:

$$
\begin{aligned}
& \operatorname{In}\left(\frac{\Sigma \operatorname{pr}(\mathrm{Y} \leq \mathrm{j} \mid \mathrm{x})}{1-\Sigma \operatorname{pr}(\mathrm{Y} \leq \mathrm{j} \mid \mathrm{x})}\right)=\alpha_{\mathrm{j}}+\beta_{\mathrm{i}} \mathrm{x}_{\mathrm{i}, 1}, \\
& \mathrm{i}=1 \ldots \mathrm{k}, \mathrm{j}=1,2, \ldots, \quad \mathrm{p}-1
\end{aligned}
$$

Where:

$$
\begin{array}{ll}
\alpha_{\mathrm{j}} \text { or } \beta_{\mathrm{o}} & =\text { Called threshold } \\
\beta_{\mathrm{I}} & =\text { Parameter } \\
\mathrm{X}_{\mathrm{i} 1} & =\text { Sets of factors or predictors }
\end{array}
$$

Equation 3 above is an ordinal logistic model for $\mathrm{k}$ predictors with P-1 levels response variable.

Model fitting and statistical software: The above model is fit to the data in Table 1 using STATA software with ordinal outcomes (ordered logit) link function specification. The model is fit through the procedure of maximum likelihood estimation. Peterson and Harrell (1990), however warned against the use of the score test

\begin{tabular}{|c|c|c|}
\hline & $\mathrm{N}$ & Marginal (\%) \\
\hline \multicolumn{3}{|l|}{ Response } \\
\hline Livebirth & 57 & 57.00 \\
\hline Stillbirth & 32 & 32.00 \\
\hline Abortion & 11 & 11.00 \\
\hline \multicolumn{3}{|l|}{ Age } \\
\hline $35-50$ & 15 & 15.00 \\
\hline $25-34$ & 55 & 55.00 \\
\hline $15-24$ & 30 & 30.00 \\
\hline \multicolumn{3}{|l|}{ Service } \\
\hline Service available & 89 & 89.00 \\
\hline Service not available & 11 & 11.00 \\
\hline \multicolumn{3}{|l|}{ Disease } \\
\hline Yes but not treated & 2 & 2.00 \\
\hline Yes but treated & 41 & 41.00 \\
\hline No & 57 & 57.00 \\
\hline \multicolumn{3}{|l|}{ Marital } \\
\hline Married & 75 & 75.00 \\
\hline Single & 25 & 25.00 \\
\hline \multicolumn{3}{|l|}{ Antenatal } \\
\hline Regular & 35 & 35.00 \\
\hline Once in a while & 40 & 40.00 \\
\hline Not at all & 25 & 25.00 \\
\hline \multicolumn{3}{|l|}{ CS } \\
\hline Yes & 19 & 19.00 \\
\hline No & 81 & 81.00 \\
\hline \multicolumn{3}{|l|}{ Weight } \\
\hline$<2500$ & 44 & 44.00 \\
\hline$>=2500$ & 56 & 56.00 \\
\hline Valid & 100 & 100.00 \\
\hline Missing & 0 & \\
\hline Total & 100 & \\
\hline
\end{tabular}
in assessing the proportional odds and parallel slopes assumptions due to its extreme anti conservation. Hence, the graphical method was used in this study to assess the validity of these assumptions (Fig. 1).

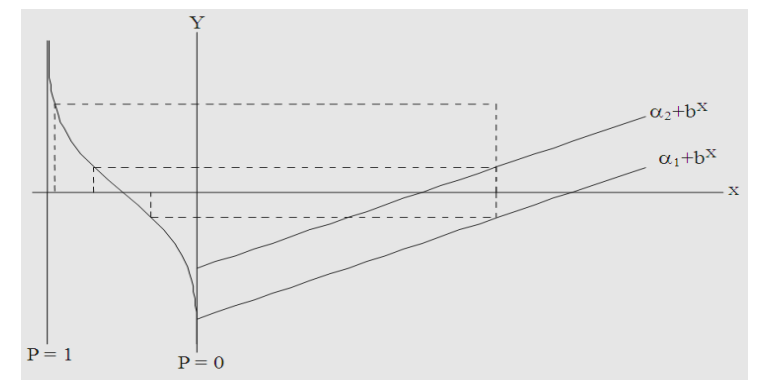

Fig. 1: Parallel regression with different intercepts and a single cut point at 0

Table 1: Summaries of data on pregnancy outcomes

The proportional odds assumption: The assumption that all the logit surfaces are parallel must be tested. A non significance test is evidence that the logit surfaces are parallel and that the odds ratio can be interpreted as constant across all possible cut point of the outcome. The intercepts in the equations may vary, but the parameters would be identical for each model. If the proportional odds assumption is not met, there are several options:

- Collapse two or more levels, particularly if some of the levels have small $n$

- Do bivariate ordinal logistic analyses, to see if there is one particular independent variable that is operating differently at different levels of the dependent variable 


\begin{tabular}{|c|c|c|c|c|c|c|}
\hline \multirow{3}{*}{$\begin{array}{l}\text { Log likelihood }=-63.024294 \\
\text { Response }\end{array}$} & \multicolumn{6}{|c|}{ Ordered logistic regression } \\
\hline & \multirow[b]{2}{*}{ Coef. } & \multirow[b]{2}{*}{ Std. Err. } & \multirow[b]{2}{*}{ Z } & \multirow[b]{2}{*}{$P>|z|$} & \multicolumn{2}{|c|}{$\begin{array}{l}\text { Number of obs } 100 \\
\text { LR chi2 }(7)=59.52 \\
\text { Prob }>\text { chi }^{2}=0.0000 \\
\text { Pseudo } R^{2}=0.3207\end{array}$} \\
\hline & & & & & $(95 \%$ conf & \\
\hline Age & 0.37198 & 0.4257 & 0.87 & 0.382 & -0.46230 & 1.2063 \\
\hline Service & -0.90907 & 0.7623 & -1.19 & 0.233 & -2.40310 & 0.5850 \\
\hline Diseases & -2.13000 & 0.5242 & -4.06 & 0.000 & -3.15760 & -1.1026 \\
\hline Marital & -0.04491 & 0.5989 & -0.07 & 0.940 & -1.21870 & 1.1288 \\
\hline Antenatal & 0.33480 & 0.3252 & 1.03 & 0.303 & -0.30260 & 0.9722 \\
\hline $\mathrm{CS}$ & -0.23943 & 0.6167 & -0.39 & 0.698 & -1.44820 & 0.9694 \\
\hline Weight & 2.90940 & 0.6515 & 4.47 & 0.000 & 1.63240 & 4.1863 \\
\hline Cut 1 & 2.72466 & 1.5011 & & & -0.21744 & 5.6667 \\
\hline Cut 2 & 5.47450 & 1.5720 & & & 2.39333 & 8.5555 \\
\hline
\end{tabular}

Table 3: Parameter estimates stating the odds ratio

\begin{tabular}{|c|c|c|c|c|c|c|}
\hline Response & Odds ratio & Std. Err. & $\mathrm{Z}$ & $\mathrm{P}>|\mathrm{z}|$ & \multicolumn{2}{|c|}{ (95\% conf. interval) } \\
\hline Age & 1.45060 & 0.6175 & 0.87 & 0.382 & 0.62970 & 3.34130 \\
\hline Service & 0.40280 & 0.3071 & -1.19 & 0.233 & 0.09042 & 1.79500 \\
\hline Diseases & 0.11880 & 0.0622 & -4.06 & 0.000 & 0.04253 & 0.33200 \\
\hline Marital & 0.95600 & 0.5728 & -0.07 & 0.940 & 0.29560 & 3.09218 \\
\hline Antenatal & 1.39760 & 0.4545 & 1.03 & 0.303 & 0.73890 & 2.64380 \\
\hline $\mathrm{CS}$ & 0.78700 & 0.4854 & -0.39 & 0.698 & 0.23500 & 2.63620 \\
\hline Weight & 18.34500 & 11.9500 & 4.47 & 0.000 & 5.11590 & 65.78260 \\
\hline Cut 1 & 2.72466 & 1.5011 & & & -0.21744 & 5.66670 \\
\hline Cut 2 & 5.47450 & 1.5720 & & & 2.39333 & 8.55550 \\
\hline
\end{tabular}

- Use the partial proportional odds model (available in SAS through PROC GENMOD)

- Use multinomial logistic regression

Application: Table 1 is the summaries of the data obtained from a State Hospital record/database of delivery in Ogun state, Nigeria. ' $\mathrm{N}$ ' shows the numbers of observations/patients belonging to each factor. For instance, Livebirth with 57 and marginal percentage to be $57 \%$ means there are 57 women with history of livebirth and proportion equal to 57 percentage livebirth.

The ordinal response variable 'pregnancy outcomes' refers to the process of the end of delivery by which a fetus leaves the mother's womb. The outcomes considered are: Live birth, Stillbirth and Abortion. Pregnancy outcomes are very sensitive to social circumstances around expectant mothers. (Kramer, 1987; Kramer et al., 2000) Socio-economic variations in infant health indicators and key pregnancy outcomes, such as infant and perinatal mortality, Low Birth Weight (LBW), intrauterine growth retardation and preterm delivery have been found in both developed and under developing countries. Logan (2003) noted that the differences in pregnancy outcome exist not simply between rich and poor but throughout the whole range of relative wealth in a population (Grjibovski, 2005). The outcome of any pregnancy is to a large extent affected by some factors which are categorized into three, namely:

- Environmental (medical service availability, previous cesareans)

- Behavioral factors (antenatal care, diseases)

- Demographic factors (age, marital status and weight)

The response variable is coded as ' 0 ' livebirth, ' 1 ' stillbirth, '2' Abortion. For the purpose of this study we will restrict all the factors to be coded as well, although factors can be either categorized or not depending on what type of factor it is. The Proportional Odds Model (POM) is fit to the data described in Table 1 and the results are summarized in Table 2.

It is convenient for some researchers to analyze ordinal outcome by means of logistic and linear regression analysis. Ordinal regression method model was used to model the relationship between ordinal outcome variable i.e., different levels of pregnancy outcomes. As earlier mentioned the model is a main effect model and assumes a linear relationship for each logit and parallel regression lines.

From Table 2, it can be deduced that Weight and diseases increase the likelihood of favoring a higher category i.e., (livebirth), while medical service 
availability, Marital status Age, Antenatal and previous cesareans reduce the likelihood/chance of having stillbirth.

For overall model, the $\mathrm{x}^{2}$ test at the upper right of Table 2 evaluates the null hypothesis that all coefficients in the model, except the constant equal zero i.e.:

$$
x^{2}=-2\left[\operatorname{InL}_{\mathrm{i}}-\operatorname{InL}_{\mathrm{f}}\right]
$$

Where:

$\mathrm{L}_{\mathrm{i}}=$ Initial iteration

$\mathrm{L}_{\mathrm{i}}=$ Final iteration

$\mathrm{x}^{2}=-2[-92.7827-(-63.0243)]=59.5$

The probability of greater $x^{2}$, with $1^{\circ}$ of freedom is low enough (0.0000) to reject the null hypothesis hence, conclude that not all factors (have influence) are equal to zero. Unlike the OLS counterpart, the ologit zapproximation/Walds and $\mathrm{x}^{2}$ test sometimes disagree. The $\mathrm{x}^{2}$ test has more general validity:

$$
\text { The pseudo }-\mathrm{R}^{2}=1-\frac{\mathrm{InL}_{\mathrm{f}}}{\mathrm{InL}_{\mathrm{i}}}=1-\left[\frac{-63.0243}{-92.7827}\right]
$$

The pseudo- $\mathrm{R}^{2}=0.3207$.

The pseudo $-\mathrm{R}^{2}$ provides a quick way to describe or compare the fit of different models for the same dependent variable, it lacks the straight forward explained-variance interpretation of true $\mathrm{R}^{2}$ in OLS regression.

Table 3 describes the odds of being in either of these categories i.e., (livebirth Vs abortion) or (stillbirth Vs abortion). This showed that women with baby's weight less than $2.5 \mathrm{~kg}$ are 18.4 times more likely to have had a livebirth than are women with babies' weight $\geq 2.5 \mathrm{~kg}$. The odds could be a little as 5.12 times or as much as 65.78 times larger with $95 \%$ confidence. For Diseases, the odds among women with history of diseases treated or not treated having a livebirth is $89 \%$ lower than women without history of diseases. The confidence interval indicates that the odds could be a little as 0.04253 times as much as 0.332 times larger with 95\% confidence. Thus, babies' weight and history of disease are significant factors of having a livebirth as pregnancy outcome.

Recall that Ordinal Logistic Regression (OLR) restrains estimation of the coefficients so that they cannot vary between transitions. That is, the slope for Age in 'Eq. 4' is the same as the slope for Age in 'Eq. 5', so as for other factors, (assumption of parallelism), only the intercept are allowed to vary. This is confirmed in Table 4 where we accept the null hypothesis of equal location parameters (slope coefficients). The $\mathrm{x}^{2}$ value of 17.45 at $10 \mathrm{df}$ is statistically not significant with the $\mathrm{x}^{2}$ value of 18.31 from table; hence, we conclude that the assumption of parallelism is satisfied.

Pooled categories

Equation 1

Equation 2

$$
1,2
$$

Pooled categories

2,3

$\mathrm{P}_{1}=2.7246+0.379 \mathrm{~A}-0.90 \mathrm{~S}-2.13 \mathrm{D}-0.44 \mathrm{M}$

$+0.334 \mathrm{An}-0.239 \mathrm{Cs}+2.9093 \mathrm{~W}$

$\mathrm{P}_{2}=5.4745+0.379 \mathrm{~A}-0.9090 \mathrm{~S}-2.13 \mathrm{D}-0.44 \mathrm{M}$ $+0.334 \mathrm{An}-0.239 \mathrm{Cs}+2.9093 \mathrm{~W}$

Figure 1 shows parallel regression with different intercepts and a single cut-point. Different hurdles have a single CDF, but several regression lines and as you can see, the lines are all parallel, or equivalently, have equal slopes. So a change in $\mathrm{X}$ makes a corresponding change in $\mathrm{Y}$, the same for any hurdle. The intercepts and the cut point can be used to calculate predicted probabilities for a woman with a given set of characteristics of being in a particular category.

Alternatively, other diagnostics that is used to determine goodness of fit can be seen from Table 5, the first row shows the values of Pearson chi-square statistics computed by covariate pattern. The reported p-value 0.827 compared with $\alpha$ value of 0.05 showed that the overall model is fit. Same as deviance $x^{2}$ in the second row of same Table 5 .

Predicted probability: Predicted probability calculates the probabilities for each category of the dependent variable. Ordered logit model estimates a score 'P' as a linear function of Age, Service, Marital status, Antenatal, Previous cesareans and Weight:

$$
\begin{aligned}
\mathrm{P}_{1}= & 207246+0.379 \mathrm{~A}-0.9090 \mathrm{~S}-2.13 \mathrm{D}-0.44 \mathrm{D} \\
- & 0.44 \mathrm{M}+0.334 \mathrm{n}-0.239 \mathrm{Cs}+2.9093 \mathrm{~W} \\
\mathrm{P}_{2}= & 5.4745+0.379 \mathrm{~A}-0.9090 \mathrm{~S}-2.13 \mathrm{D} \\
& -0.44 \mathrm{M}+0.334 \mathrm{An}-0.23 \mathrm{Cs}+2.9093 \mathrm{~W}
\end{aligned}
$$

Table 4: Test of parallel lines

\begin{tabular}{lllll}
\hline Model & -2 Log likelihood & Chi-square & df & Sig. \\
\hline Null hypothesis & 109.81 & & & \\
General & $92.360(a)$ & $17.450(\mathrm{~b})$ & 10 & 0.173 \\
\hline
\end{tabular}

Table 5: Goodness of fit

\begin{tabular}{llll}
\hline & Chi-square & df & Sig. \\
\hline Pearson & 109.113 & 124 & 0.827 \\
Deviance & 100.152 & 124 & 0.943 \\
\hline
\end{tabular}


Predicted probabilities depend on the value of $\mathrm{P}_{\mathrm{s}}$ plus a logically distributed disturbance $\mu$ relative to the estimated cut points:

$$
\text { Let } \begin{aligned}
\mathrm{P}_{\mathrm{s}}= & 0.379 \mathrm{~A}-0.9090 \mathrm{~S}-2.13 \mathrm{D}-0.44 \mathrm{M} \\
& +0.334 \mathrm{M}+0.239 \mathrm{Cs}+2.9093 \mathrm{~W}
\end{aligned}
$$

Then:

$$
\begin{aligned}
& \mathrm{P}(\text { Livebirth }=0)=\mathrm{P}\left(\mathrm{P}_{\mathrm{s}}+\mu \leq{ }_{-} \text {cut } 1\right)=\mathrm{P}\left(\mathrm{P}_{\mathrm{s}}+2.7246\right) \\
& \mathrm{P}\left(\text { Stillbirth =1) }=\mathrm{P}\left({ }_{\text {c cut } \left.1 \leq \mathrm{P}_{\mathrm{s}}+\mu \leq{ }_{\text {_cut }}\right)}\right)\right. \\
& =\mathrm{P}\left(2.7246<\mathrm{P}_{\mathrm{s}}+<5.4745\right) \\
& \mathrm{P}\left(\text { Abortion = 2) }=\mathrm{P}\left(\text { _cut } 2<\mathrm{P}_{\mathrm{s}}+\mu\right)\right. \\
& =\mathrm{P}\left(5.4745<\mathrm{P}_{\mathrm{s}}+\mu<\right)
\end{aligned}
$$

\section{Model selection:}

Stepwise regression: At the beginning of stepwise search of Table 6, no X-variable is in the model so that the model to be fitted is in $\gamma \mathrm{i}=\alpha_{j}+\varepsilon_{\mathrm{i}}$

In step 1, the corresponding t-statistics are calculated for each potential $\mathrm{X}$ - variable and the predictor having the highest $\mathrm{t}$-value is chosen to enter the equation. We see that Age $\left(\mathrm{X}_{1}\right)$ has the biggest $\mathrm{t}$ value. The disease is drop as the t-value of Age falls above table value i.e., $\mathrm{T}_{(0.05,99)}=1.661$ Hence, Age is added. The current regression model contains age $\left(\mathrm{X}_{1}\right)$ on the output displayed. Weight $\left(\mathrm{X}_{7}\right)$ has the biggest $\mathrm{t}$ value and it falls above 1.661. The column labeled step 2 shows the situation at this point. Age and Weight $\left(X_{1}\right.$, $\mathrm{X}_{7}$ ) are now in the model and the information about this model is provided and consideration of dropping $X_{1}$ is uphold and this is not possible because the t-value is still greater than 1.661. Hence the variable is retained. Next all regression models contain $X_{1}$ and $X_{7}$, the column labeled step 3 summarized the situation at this point where $\mathrm{X}_{2}$ (Medical Service Availability) is dropped because the t-value is quite lower than table value of 1.661. A test is taken to determine whether $X_{1}$ or $\mathrm{X}_{7}$ should be dropped since all $\mathrm{t}$-values are greater than table value, then both variables are retained and $\mathrm{X}_{2}$ is dropped. Thus, the stepwise search algorithms continue until the last variable.

At the bottom of the column is variable selection criteria $R^{2}$ and observing at the result of $R^{2}$, the $R^{2}$ with the highest value and minimum standard error of 0.534 is $42.71 \%$. Thus, the stepwise search algorithms identified Age, Weight and Disease $\left(X_{1}, X_{7}\right.$ and $\left.X_{3}\right)$ as the 'best' subset of $\mathrm{x}$ variable. This model also happens to be the model identified by both $\mathrm{SBC}_{\mathrm{p}}$ and $\mathrm{PRESS}_{\mathrm{p}}$ criteria.

Best subset regression: The MINITAB algorithms Table 7, for each of the "BEST" subset $\mathrm{R}_{\mathrm{P}}^{2}, \mathrm{R}_{\mathrm{a} P}^{2}, \mathrm{C}_{\mathrm{P}}$ and $\sqrt{M S E}$ (labeled $S$ ) values. From the output of Minitab, it was observed that the best subset. According

\begin{tabular}{|c|c|c|c|c|c|}
\hline \multicolumn{3}{|c|}{ F-to-enter: 0.005} & \multicolumn{3}{|c|}{ F-to-remove: 0.05} \\
\hline Step & 1 & 2 & 3 & 4 & 5 \\
\hline Constant & 0.9238 & 0.00191 & 0.01699 & -0.0183 & 0.0301 \\
\hline Age & 0.2040 & 0.12600 & 0.13500 & 0.1210 & 0.1270 \\
\hline T-Value & 2.1700 & 1.52000 & 1.62000 & 1.4300 & 1.4800 \\
\hline Disease & -0.5300 & -0.45000 & -0.47000 & -0.4500 & -0.4500 \\
\hline T-Value & -4.6200 & -4.50000 & -4.59000 & -4.3600 & -4.3000 \\
\hline Weight & & 0.62000 & 0.62000 & 0.6100 & 0.6000 \\
\hline T-value & & 5.64000 & 5.66000 & 5.4600 & 5.3400 \\
\hline Service & & & -0.18000 & -0.1900 & -0.1800 \\
\hline T- Value & & & -1.02000 & -1.1100 & -1.0100 \\
\hline & & & & 0.0 & 0.0770 \\
\hline T-Value & & & & 0.9900 & 1.0400 \\
\hline CS & & & & & -0.0800 \\
\hline T-Value & & & & & -0.5300 \\
\hline S & 0.6130 & 0.5340 & 0.5340 & 0.5340 & 0.5360 \\
\hline $\mathrm{R}-\mathrm{Sq}$ & 22.0700 & 41.4700 & 42.1100 & 42.7100 & 42.8800 \\
\hline
\end{tabular}
to the $\mathrm{R}_{\mathrm{a} p}^{2}$ criterion, is either the three-parameter model based on $\left(\mathrm{X}_{1}, \mathrm{X}_{3}\right.$ and $\left.\mathrm{X}_{7}\right)$ and four-parameter model

\begin{tabular}{|c|c|c|c|c|c|c|c|c|c|c|c|}
\hline \multirow[b]{2}{*}{ Var } & \multicolumn{11}{|c|}{ Response is response } \\
\hline & $\mathrm{R}-\mathrm{Sq}$ & R-Sq Adj & C-p & $\mathrm{S}$ & Age & Service & Diseases & Marital & Antenatal & Cs & Weight \\
\hline 1 & 27.3 & 26.6 & 21.1 & 0.58935 & & & & & & & $\mathrm{X}$ \\
\hline 1 & 18.3 & 17.5 & 35.6 & 0.62488 & & & & & & & \\
\hline 2 & 40.1 & 38.8 & 2.6 & 0.53798 & & & & & & & $X$ \\
\hline 2 & 29.7 & 28.2 & 19.3 & 0.58266 & & & $\mathrm{X}$ & & & & $X$ \\
\hline 3 & 41.5 & 39.7 & 2.3 & 0.53425 & $X$ & & & & & & $\mathrm{X}$ \\
\hline 3 & 40.9 & 39.0 & 3.3 & 0.53712 & & & $X$ & & $X$ & & $X$ \\
\hline 4 & 42.1 & 39.7 & 3.3 & 0.53425 & $\mathrm{X}$ & $\mathrm{X}$ & X & & & & $X$ \\
\hline 4 & 42.0 & 39.5 & 3.5 & 0.53494 & X & & $\mathrm{X}$ & & $X$ & & $X$ \\
\hline 5 & 42.7 & 39.7 & 4.3 & 0.53432 & $X$ & $X$ & $\mathrm{X}$ & & $X$ & & $X$ \\
\hline 5 & 42.3 & 39.2 & 5.0 & 0.53641 & $\mathrm{X}$ & $\mathrm{X}$ & $\mathrm{X}$ & & $\mathrm{X}$ & $\mathrm{X}$ & $\mathrm{X}$ \\
\hline 6 & 42.9 & 39.2 & 6.0 & 0.53638 & $\mathrm{X}$ & $\mathrm{X}$ & $X$ & & $\mathrm{X}$ & $\mathrm{X}$ & $\mathrm{X}$ \\
\hline 6 & 42.7 & 39.0 & 6.3 & 0.53709 & $\mathrm{X}$ & $X$ & $\mathrm{X}$ & $X$ & $X$ & & $\mathrm{X}$ \\
\hline 7 & 42.9 & 38.5 & 8.0 & 0.53920 & $\mathrm{X}$ & $\mathrm{X}$ & $\mathrm{X}$ & $\mathrm{X}$ & $\mathrm{X}$ & $\mathrm{X}$ & $\mathrm{X}$ \\
\hline
\end{tabular}
based on $\left(X_{1}, X_{2}, X_{3}\right.$ and $\left.X_{7}\right)$ except $X_{2}$, the $R_{a p}^{2}$ criterion value for these models is 0.397 or $39.7 \%$.

Table 6: Stepwise regression

Response is response on 7 predictors, with $\mathrm{N}=100$

Table 7: Best subset regression 
All possible regression procedure leads to the identification of a small number of subsets that are "good" according to a specified criterion. $\mathrm{SBC}_{\mathrm{p}}, \mathrm{AIC}_{\mathrm{p}}$ and PRESS $_{p}$ can also be used as criteria. After rerunning the analysis, the results showed that model with 3-variable (Age, diseases and weight) had the best/good result. Hence model with three variables is a most parsimonious model.

\section{RESULTS}

The study showed that the estimated odds are 18.34, 1.5, 1.4 times in favor of an individual having baby's weight less than $2.5 \mathrm{~kg}$, that is babies with weight less than $2.5 \mathrm{~kg}$ is 18 times more likely to occur than babies with weight $\geq 2.5 \mathrm{~kg}$ and at the same time Age (older age and middle aged) women are one halve (1.5) more likely to occur than lower aged women, So also is Antenatal (high parity and low parity) are more likely to occur 1.5 times than nullipara.

Thus, recommended that any pregnant woman of middle age and above, even with past history of diseases and an outcome weight less $2.5 \mathrm{~kg}$ can result into a livebirth if proper medical service is available.

\section{DISCUSSION}

Suggestion for further study: The ordinal regression model is strictly built on the model assumption of parallel lines (i.e., same regression coefficients) for all corresponding outcomes categories. If the verification of model assumption fails, the multinomial logistic regression model that does not require the assumption should become an alternative tool. In multinational logistic regression, the outcome variable is categorized as the nominal group-the target group and the reference group. For example livebirth is coded-0, still birth coded-1 and abortion is treated as the reference group.

Two models equations are generated from the nominal outcome with three categories, the two sets of relative risk are calculated when two sets of relative risk are calculated when the problem of individual falling into specific target category (j) is compared to these individuals in the reference category $(\mathrm{k})$, e.g., $\mathrm{P}$ $\left(\mathrm{Y}=\mathrm{y}_{\mathrm{i}}\right) / \mathrm{P}\left(\mathrm{Y}=\mathrm{y}_{\mathrm{k}}\right)$.

The magnitude of the effect of a specific explanatory variable can be expressed as an average of one unit change on explanatory variables affects on the change of the relative risk of individual pregnancy resulting in a target category rather than advancing for the reference category.

\section{CONCLUSION}

The objectives of the study were achieved with the use of STATA-package version 9.0 and Minitab 15.0. Finally, the model assumes that the relationship between ordinal outcome and explanatory variable is independent of categories. Thus, the assumption implies that the corresponding regression coefficient in the link function is equal for each category. Therefore, it is easy to construct and interpret the ordinal regression model, which requires only one model assumption and produce only one set of regression coefficients.

\section{ACKNOWLEDGEMENT}

In the process of writing a project like this, one is bound to acknowledge certain form of indebtedness during the work on the project.

Dr. (Mrs.) A.A. Adepoju, my principle supervisor, advisor and role model. Working with Adepoju for some times has been a true and completely undeserved privilege, for which I am indeed grateful.

My regards to Chief Matron, Nurse Odusanya and others at the Ijebu Ode State hospital who gave me supports during data collection stage.

\section{REFERENCES}

Adepoju, A.A. and M. Adegbite, 2009. Application of ordinal logistic regression model to occupational data. J. Sci. Ind. Stud., 7: 39-49.

Agresti, A., 2007. An Introduction to Categorical Data Analysis. 2nd Edn., Wiley, New York, ISBN: 10: 0471226181, pp: 400.

Ananth, C.V. and D.G. Kleinbaum, 1997. Regression model for ordinal responses: A review of methods and applications. Int. J. Epidemiol., 26: 1323-1332.

Dayton, C.M., 1992. Logistic regression analysis. University of Maryland. http://bus.utk.edu/stat/datamining/Logistic\%20Reg ression\%20Analysis\%20(Dayton).pdf

Dong, Y., 2007. Logistic regression models for ordinal response. Texas Medical Center Dissertations. http://digitalcommons.library.tmc.edu/dissertations /AAI1444593/

Grjibovski, A., 2005. Socio-demographic determinants of pregnancy outcomes and infant growth in transitional Russia. Karolinska University Press. http://diss.kib.ki.se/2005/91-7140-226-8/thesis.pdf

Hosmer, D.W. and S. Lemeshow, 2000. Applied Logistic Regression. 2nd Edn., Wiley, New York, ISBN: 10: 0471356328, pp: 392. 
Kramer, M.S., L. Seguin, J. Lydin and L. Goulet, 2000. Socio-economic disparities in pregnancy outcome: Why do the poor fare so poorly? Paediatr. Perinat. Epidemiol., 14: 194-210. DOI: 10.1046/j.13653016.2000.00266.x

Kramer, M.S., 1987. Intrauterine growth and gestational duration determinants. Pediatrics, 80: 502-511.

Lall, R., M.J. Campbell and S.J. Walters, 2002. A review of ordinal regression models applied on health quality of life assessments. Stat. Methods Med. Res., 11: 49-67. DOI: 10.1191/0962280202sm271ra
Logan, S., 2003. Research and equity in child health. Pediatrics, 112: 759-762. DOI: $10.1542 /$ peds

McCullagh, P., 1980. Regression models for ordinal data. J. R. Stat. Soc., 42: 109-142.

Peterson, B. and F.E. Harrell Jr., 1990. Partial proportional odds models for ordinal response variables. Applied Stat., 39: 205-217. DOI: $10.2307 / 2347760$

Walker, S.H. and D.B. Duncan, 1967. Estimation of the probability of an event as a function of several independent variables. Biometrika, 54: 167-179. DOI: $10.2307 / 2333860$ 